\title{
DO DEVER E GARANTIA DA FUNDAMENTAÇÃO DAS DECISÕES JUDICIAIS SOB O PARADIGMA DO NOVO CÓDIGO DE PROCESSO CIVIL: UMA CONSOLIDAÇAO DO ESTADO DEMOCRÁTICO DE DIREITO
}

\section{THE OBLIGATION AND WARRANTY TO STATE REASONS OF JUDICIAL DECISIONS UNDER THE PARADIGM OF THE NEW CODE OF CIVIL PROCEDURE: A RIGHT OF DEMOCRATIC STATE OF CONSOLIDATION}

\author{
Quezia Dornellas Fialho ${ }^{1}$
}

\section{RESUMO}

O Estado Constitucional exige guarida aos direitos fundamentais dentro do processo. O dever, e ao mesmo tempo a garantia, de fundamentação das decisões judiciais deve, juntamente com outros princípios processuais, dar azo a uma nova maneira de pensar o processo, não visando a celeridade a qualquer custo, mas a realização segura dos direitos fundamentais das partes durante a marcha processual. Assim, no tocante a este dever-garantia, o novo código de processo civil inovou ao estabelecer requisitos objetivos para a fundamentação adequada das decisões judiciais.

Palavras-chave: Estado Constitucional. Princípios fundamentais. Fundamentações das decisões judiciais. Novo código de processo civil. Art. 489.

\begin{abstract}
The constitutional state requires den to fundamental rights within the process. The duty, while the guarantee, the evidence of judicial decisions should, together with other procedural principles, lead to a new way of thinking about the process, not aiming at the speed at any cost, but the safe conduct of the fundamental rights of parties during the procedural motion. Thus, with respect to this duty-assurance, the new Code of Civil Procedure innovated by establishing requirements for the goals adequate reasoning of judgments.
\end{abstract}

Keywords: Constitutional State. Democratic State of Right. Fundamental principles. Foundations of judgments. New Code of Civil Procedure . Article 489.

\footnotetext{
${ }^{1}$ Mestranda em Direito Processual pela Universidade Federal do Espírito Santo - UFES, Espirito Santo (Brasil). Advogada. Especialista em Direito Processual Civil. E-mail: dornellasfialho@gmail.com
} 


\section{Das considerações iniciais}

Sendo o Estado o detentor da Jurisdição (monopólio da administração da Justiça - princípio da inafastabilidade), nada mais coerente que, dentro de um contexto democrático constitucional, seus atos sejam no mínimo justificados perante os seus jurisdicionados.

A sentença judicial, como o maior ato típico de comando (norma jurídica individualizada), na qual se encerra elemento lógico e volitivo, é utilizada por Cruz e Tucci como objeto de sua obra para discorrer, a partir dela, mas não somente, sobre o dever de motivação, como fenômeno endoprocessual de comunicação e de atividade crítica-intelectual do magistrado, dos atos judiciais em geral. ${ }^{2}$

Caso o juiz não demarque precisamente a trilha optada para a justiça realizada, o arbítrio dá lugar aos caos e à insegurança, uma vez que a sentença não resulta de simples mecanismo de lógica jurídica, silogismo ou operação aritmética, mas também de elementos principiológicos e regras formais. É a função justificadora da decisão que a torna controlável quanto à sua racionalidade, visando sempre não apenas convencer as partes e/ ou as instâncias superiores, mas também a opinião pública. ${ }^{3}$

O que se entende por decisão fundamentada? Barbosa Moreira afirma que "tem variado, no espaço e no tempo, o próprio entendimento de decisão motivada", ${ }_{4}^{4}$ ou seja, os requisitos que devem ser satisfeitos para que se tenha por cumprido o dever de fundamentar os pronunciamentos judiciais são mutáveis no tempo e no espaço.

Recorrendo-se à lexicologia, fundamentar é verbo transitivo direto que designa "lançar os fundamentos ou alicerces de; demonstrar através da lei, da doutrina, da jurisprudência, ou de

\footnotetext{
2 TUCCI, José Rogério Cruz e. A motivação da sentença no processo civil. São Paulo: Saraiva, 1987, p. 07-14.

${ }^{3}$ WAMBIER, Teresa Arruda Alvim. Nulidades do processo e da sentença. 6 a ed. São Paulo: RT, 2007, p. 316317.

${ }^{4}$ MOREIRA, José Carlos Barbosa. A motivação das decisões judiciais como garantia inerente ao Estado de Direito. In: Temas de direito processual. 2a série. São Paulo: Saraiva, 1998, p. 84-86.
} 
provas (aquilo que a parte alega em juízo) com o fim de obter uma decisão favorável; apoiar (-se) em fundamentos; fundar(-se), documentar(-se), justificar(-se).",5

O conteúdo da motivação ou fundamentação das decisões judiciais em geral, então, apresentase como o principal meio pelo qual o magistrado valora, não apenas indica, as provas produzidas que determinaram a ratio decidendi, ante as circunstâncias de fato e de direito do caso. Por isso seu conteúdo deve ser expresso claro, coerente e lógico. ${ }^{6}$

Fundamentar um julgado serve para demonstrar e fazer impor a vontade da lei tanto às partes do processo quanto a toda a coletividade, ao mesmo tempo em que serve como uma forma de controle público quanto aos limites do julgado (por meio da via difusa da democracia participativa), além de uniformizar a jurisprudência. Por isso que fundamentar decisão cumpre dupla função: endo e extraprocessual. ${ }^{7}$

E quais seriam, neste contexto, os motivos da exigência do juiz sempre motivar suas decisões? Michelle Taruffo, evidenciando sobremaneira a sua função extraprocessual, entende que a principal razão seria a garantia do controle público do agir democrático do Estado-Juiz:

La prima di queste "anime" è strettamente legata alle esigenze di funzionamento del
processo e di organizzazine centralizzata della magistratura. (...) La seconda
"anima" dell'obbligo di motivazione, che non ne esclude la funzione
razionalizzatrice del sistema, ma la supera, si fonda sulla concezione della
motivazione come garanzia. (...) L'obbligo di motivazione è dunque elemento
essenziale di un ideologia democratica della giustizia, cui appartengono altri principi
fondamentali, come ad es quello della pubblicità delle procedure giudiziarie. (...)
L'obbligo costituzionale di motivazione nasce infatti dalla crisi dello Stato persona,
autocratico ed estraneo rispetto alla società civile, e dal conseguente affermarsi del
principio per cui la sovranità spetta al popolo. Sul piano della giurisdizione, ciò
significa che la giustizia non è più uma manifestazione della volontà del sovrano, o
del führerprinzip, ma risulta dall'esercizio di um potere che il popolo ha delegato
giudice.

${ }^{5}$ DICIONÁRIO HOUAISS, http://houaiss.uol.com.br. Acesso em: 20 de julho de 2015.

${ }^{6}$ TUCCI, 1987, p. 18-21.

${ }^{7}$ TUCCI, 1987, p. 27.

${ }^{8}$ TARUFFO, Michele. Il significato constituzionale dell'obbligo di motivazione. In: Participação e Processo (Coord.: Dinamarco, Grinover e Watanabe). São Paulo: RT, 1988, p. 37-41. A primeira dessas "buscas" está intimamente ligada aos requisitos de operação do processo e organização centralizada membros do poder judiciário. (...) A segunda obrigação "busca" de fundamentação, que não exclui a função de racionalizar o sistema, mas vai além, baseia-se no conceito de motivação como garantia. (...) A exigência é, portanto, um 
Afastando-se de exegeses justificadoras ligadas aos sentimentos e à consciência do magistrado ao proferir uma decisão e sua consequente motivação, ${ }^{9}$ Liebman coaduna com a ideia objetiva da obrigatoriedade inerente ao Estado, visando convencer não só as partes, mas também a opinião pública (controle generalizado difuso ou extraprocessual) ${ }^{10} \mathrm{e}$, com isso, reforçar a confiança na tutela jurisdicional:

\begin{abstract}
Instituição e raciocínio concorrem, em diversas medidas, para formar o juízo e é inútil tentar estabelecer regras e ordens nos elementos e os casos são infinitos. Para o direito é irrelevante conhecer dos mecanismos psicológicos que, às vezes, permitem ao juiz chegar às decisões. O que importa, somente, é saber se a parte dispositiva da sentença e a motivação estão, do ponto de vista jurídico, lógicos e coerentes, de forma a constituírem elementos inseparáveis de um ato unitário, que se interpretam e se iluminam reciprocamente. ${ }^{11}$
\end{abstract}

Segundo Liebman, então, quando a lei impõe a obrigatoriedade das decisões serem fundamentadas, tal motivação deve constituir uma etapa anterior à decisão. Somente assim, criar-se-ia uma efetiva garantia contra o arbítrio. De qualquer forma, o próprio autor conclui que a intuição e o raciocínio concorrem, em diversas medidas, para forma o juízo e é inútil tentar estabelecer ordens nesses elementos. O que importa é saber se a parte dispositiva e a motivação da sentença estão, juridicamente, lógicas e coerentes, de forma a constituírem um ato único.

Cabe salientar que o dever de motivação extraprocessual pode ser analisado sob diversas perspectivas, conforme lição de Barbosa Moreira, a saber, como técnica ou política legislativa (i), uma vez que as decisões bem motivadas barram recursos, permite o contraditório e uniformiza jurisprudência; como potencializador principiológico (ii), reforçando a

elemento essencial de uma ideologia democrática da justiça, que pertencem outros princípios básicos, como a publicidade dos processos judiciais. (...) A obrigação constitucional de motivação foi inspirada pela crise da pessoa do Estado, autocrático e estranho à sociedade civil, e a consequente afirmação do princípio de que a Soberania reside no povo. Em termos de Jurisdição, significa que a justiça não é somente manifestação da vontade do Soberano, princípio da führerprinzip, mas do exercício do poder que o povo delegou ao juiz.

9 Neste sentido: "O julgamento vem primeiro, o raciocínio depois." CARNELUTTI, Francesco. Diritto $e$ Processo. Giuffré Editora: Nápoles, 1958, p. 215.

${ }^{10}$ CARNEIRO, Athos Gusmão. Sentença mal fundamentada e sentença não fundamentada. In: RePro, n. 81, São Paulo: RT, 1996, p. 220-221.

${ }^{11}$ LIEBMAN, Enrico Tulio. Do arbítrio à razão. Reflexão sobre a motivação da sentença. In: RePro, n. 29. São Paulo: RT, 1983, p. 79-81. 
legitimidade das decisões, a imparcialidade e a independência do magistrado (barreira ir contra o puro arbítrio e o clientelismo); e como substrato do Estado Democrático de Direito (iii), tendo em vista que o dever de motivar funciona como prestação de contas ao poder constitucional que foi delegado ao Poder Judiciário pelo povo. ${ }^{12}$ De fato, “o Estado de Direito efetivamente caracteriza-se por ser o Estado que se justifica, tendo como pauta a ordem jurídica a que ele próprio se submete."13

Segundo Barbosa Moreira, a necessidade de fundamentação das decisões é, antes de tudo, uma questão ligada a princípios fundamentais de ordem política. ${ }^{14}$

Isso quer dizer que o tratamento mais moderno do tema perpassa o aspecto técnico do dever de motivação endo e extraprocessual, alcançando o plano dos princípios fundamentais. Princípios estes que devem conduzir a atividade estatal e jurisdicional e, assim, avulta a ideia de garantia como inspiração básica do dever de fundamentar as decisões jurídicas, o que justifica, portanto, sua obrigatoriedade e publicidade. ${ }^{15}$

\section{Do regramento constitucional e legal processual vigente (CPC de 1973) acerca do dever de motivação das decisões judiciais}

Antes da segunda metade do século XVIII, de forma geral, não existia a obrigação de fundamentar as decisões judiciais, salvo algumas exceções. Com as revoluções burguesas deste período histórico e o surgimento do liberalismo político (supressão das arbitrariedades estatais do regime feudal e do direito canônico), o estado de direito exsurge, passando-se a delinear de maneira efetiva o instituto da fundamentação das decisões da maneira que o conhecemos hoje. ${ }^{16}$ Barbosa Moreira complementa:

\footnotetext{
${ }^{12}$ MOREIRA, 1998, p. 86-88.

${ }^{13}$ WAMBIER, 2007, p. 313-314.

${ }^{14}$ MOREIRA, 1998, p. 87.

${ }^{15}$ MOREIRA, 1998, p. 87-91.

16 TUCCI, 1987, p. 27.
} 
Registra a história do direito precedentes antigos de decisões judiciais que precisavam ou costumavam ser motivadas. A partir da segunda metade do século XVIII, porém, é que se começou a generalizar, nas legislações ocidentais, a exigência feita aos juízes de declarar, em seus pronunciamentos decisórios, as razões em que se baseavam - imposição em regra qualificada pelo requisito da publicidade (...). A obrigatoriedade da motivação constituiria traço comum a quase todas as grandes codificações processuais do século XIX. ${ }^{17}$

É importante salientar que até 1988 inexistia previsão expressa quanto a obrigatoriedade de motivar as decisões judiciais, sendo a exegese extraída da legislação infraconstitucional. Por isso, a doutrina considerava a obrigatoriedade de fundamentação uma cláusula constitucional implícita.

A Constituição Federal (CF88) que estatui a necessidade de serem fundamentadas as decisões judiciais. As leis ratificam tal exegese. Na verdade, o dever de motivação das decisões judiciais (que tem origem desde as ordenações Filipinas) previsto no art. 93, inciso IX, nada mais faz o que tornar expresso princípio constitucional que existia antes de a regra explícita existir, já que é manifestação do Estado de Direito, conforme aduzimos acima. ${ }^{18}$

A sistemática adotada por meio dos incisos XXXV, LIV e LV do art. $5^{\circ}$ da CF88, por si só, tornaria dispensável a previsão expressa do art. 93, podendo ser detectada dentre o conjunto de garantias que formam o processo justo. ${ }^{19}$

Ao lado da CF88, o Código de Processo Civil vigente (CPC de 1973), mormente nos artigos 131, 165 e 458 (requisitos da sentença), estabelece o regramento básico.

O princípio do livre convencimento motivado, bem como a incidência da regra do iura novit curia, está presente no art. 131, no qual estabelece que o juiz apreciará livremente a prova, atentando-se aos fatos e fundamentos do caso, mesmo que não relatados nos autos pelas partes, mas indicando sempre os motivos do seu convencimento.

\footnotetext{
${ }^{17}$ MOREIRA, 1998, p. 94.

${ }^{18}$ WAMBIER, 2007, p. 313.

${ }^{19}$ WAMBIER, 2007, p. 313.
} 
$\mathrm{O}$ art. 165 dispõe que as sentenças e os acórdãos deverão ser proferidos com seus requisitos essenciais, dentre eles, os fundamentos, em que o juiz analisará as questões de fato e de direito. Ainda, dispõe que as demais decisões (decisões interlocutórias e despachos) serão fundamentadas até mesmo de modo conciso.

Cumpre dizer que a ratio decidendi das decisões interlocutórias é legada à discricionariedade do magistrado, que a exporá da forma que lhe parecer oportuno, conforme ensinamento de Cruz e Tucci. ${ }^{20}$

Há outra exceção à regra de fundamentação rígida que aferimos do art. 459, que trata dos casos de extinção do processo sem julgamento do mérito.

Acontece que mesmo se tratado de sentença de mérito, há hipóteses em que não implicam fundamentação mais pormenorizada, a saber, as hipóteses previstas no art. 269, incisos II a V, do CPC vigente (quando o réu reconhecer a procedência do pedido; quando as partes transigirem; quando o juiz pronunciar a decadência ou a prescrição; quando o autor renunciar ao direito sobre que se funda a ação).

Em se tratando de Juizados Especiais, em que o processo se orienta por critérios próprios (oralidade, simplicidade, informalidade, economia processual e celeridade), as decisões judiciais voltam e meia têm sido frequentemente questionadas pela parca fundamentação e dialeticidade empregada no julgamento.

Neste contexto, ainda, questiona-se a validade da permissão do art. 46 da Lei n. 9.099/95 que autoriza a confirmação da sentença pelos seus próprios fundamentos pelo órgão ad quem, além da prescindibilidade do relatório.

${ }^{20}$ TUCCI, 1987, p. 88. 
Há de se entender que simplificação do procedimento não significa ausência ou deficiência de fundamentação.

Toda e qualquer decisão necessita de justificativa, de explanação demonstrativa de adequação entre a subsunção do caso à norma, o que não significa que toda e qualquer decisum necessite de serem extensa, porém deve abarcar todas as questões relevantes para a justificação do dispositivo da sentença, mesmo em sede de juizado especial. O juiz deve expor, mesmo que sucintamente, mas de forma contundente, os elementos que o levaram a decidir, uma vez que a motivação é a explicação da sua convicção. ${ }^{21}$

João Batista Lazzari traz interessante abordagem da teoria da Argumentação Jurídica de Manoel Atienza, demonstrando que nos juizados tramitam causas fáceis (de menor complexidade) e causas de difícil solução (embora de baixo valor monetário). A solução de casos fáceis encontra compatibilidade com seus princípios próprios. Nos casos difíceis, as questões suscitadas pelas partes merecem resposta pontual, devendo ser afastada a técnica da confirmação da sentença pelos próprios fundamentos. ${ }^{22}$

Em suma, adotando-se a classificação de José Rogério Cruz e Tucci, as decisões que exigem motivação complexa são as sentenças e os acórdãos definitivos (que resolvem o mérito da causa) e as decisões que não exigem motivação complexa (sendo, portanto, concisas) são as decisões interlocutórias, as sentenças proferidas em âmbito dos juizados especiais e no âmbito dos procedimentos de jurisdição voluntária. ${ }^{23}$

No que tange à falta ou débil motivação, a decisão será absolutamente nula.

\footnotetext{
${ }^{21}$ MARINONI, Luiz Guilherme; ARENHART, Sérgio Cruz. Manual do processo de conhecimento. $4^{\mathrm{a}}$ Ed. São Paulo: RT, 2005, p. 457.

${ }^{22}$ LAZZARI, João Batista. A argumentação jurídica e a fundamentação das decisões proferidas no âmbito dos juizados especiais. Revista Jurídica, v. 18, n. 35, p. 215-229, jan./abr. 2014.

23 TUCCI, 1987, p. 152.
} 
$\mathrm{Na}$ praxe forense é infelizmente comum nos depararmos com decisões que têm por fundamento somente ementas de outros julgados, transcrição integral de dispositivos legais, súmulas, enunciados, entre outros textos isolados, sem a necessária subsunção destes ao caso concreto.

No caso de decisão interlocutória, a nulidade somente será decretada a requerimento de qualquer das partes ou mesmo de oficio se dela restar prejuízo (por exemplo, decisão que decreta a prisão do devedor de alimentos ou a decisão que indefere a produção de certa prova). ${ }^{24}$

Acerca de decisório não fundamentado, mal fundamentado e insuficientemente fundamentado, Athos Gusmão Carneiro constrói suas pertinentes observações e adverte que sentença sucinta (aquela que não deixa de conter o essencial) não é nula:

\begin{abstract}
A sentença apenas suscintamente fundamentada, em que as questões controvertidas hajam sido consideradas com sumariedade e singeleza, não serão modelares e muito menos aconselháveis; mas não serão nulas, cabendo uma relativa tolerância, máxime se os temas em debate forem simples e várias vezes já resolvidos no sentido adotado na sentença. (...) A sentença com fundamentação sucinta, todavia, não deverá ser confundida com a sentença deficiente, incompleta em sua fundamentação. O juiz, por certo, não está adstrito a responder, um a um, os argumentos das partes; tem o dever, contudo, de examinar as questões (= pontos controvertidos), todas elas, que possam servir de fundamento essencial à acolhida, total ou parcial, ou à rejeição, no todo ou em parte, do pedido formulado pelo demandante. ${ }^{25}$
\end{abstract}

De fato, decisão fundamentada suscintamente, desde que as questões controvertidas tenham sido analisadas, mesmo de forma sumária e singela, contendo o essencial, não geram nulidade.

Teresa Arruda Alvim Wambier, sobre as nulidades da sentença, especifica três vícios intrínsecos: ausência de fundamentação, deficiência de fundamentação e ausência de

\footnotetext{
${ }^{24}$ TUCCI, ibidem.

${ }^{25}$ CARNEIRO, 1996, p. 223.
} 
correlação entre fundamentação e decisório. Para a autora, todas as três hipóteses ensejam nulidade da sentença, pois uma fundamentação inadequada é o mesmo que inexistente. ${ }^{26}$

Segundo Barbosa Moreira, devem ser evitadas referências genéricas e não justificadas, como por exemplo, 'a prova produzida pelo autor não convence' ou 'as alegações do réu não ficaram comprovadas'. O juiz tem de explicar o porquê não lhe pareceu convincente as alegações e as provas produzidas pelas partes, precisa ser demonstrada na decisão como isso realmente aconteceu. ${ }^{27}$

Porém, admite-se como válida a decisão em que o juiz se reporta, em seus fundamentos, a outro ato, peças ou manifestação do processo (por exemplo, outra decisão, parecer, enunciado), o que se convenciou chamar de motivação per relationem ou aliunde, ${ }^{28}$ previsão até expressa na lei dos juizados (art. 46). ${ }^{29}$

A motivação per relationem deve ser vista como uma exceção da qual se pode valer o julgador em homenagem ao princípio da economia processual e desde que não tenha havido suscitação de fato ou argumento novo e a peça processual à qual se reporta a decisão esteja substancialmente fundamentada, bem como esteja nos autos e que a ela possam ter acesso. ${ }^{30}$

Tucci lembra que a motivação aparente ou implícita (aquela em que não há necessidade do juiz analisar todos os argumentos das partes, principalmente da parte vencida) é admissível. ${ }^{31}$

\footnotetext{
${ }^{26}$ WAMBIER, 2007, 323-327.

${ }^{27}$ MOREIRA, José Carlos Barbosa. O que deve e o que não deve figurar na sentença. In: Temas de Direito Processual. São Paulo: Saraiva, 2004, p. 121.

${ }^{28}$ Esta Corte Superior possui entendimento pacificado no sentido de admitir a fundamentação per relationem ou aliunde, que se vale da motivação contida em ato judicial anterior, bem como em manifestação ministerial, como razões da decisão judicial mediante sua transcrição. A própria defesa reconhecer a validade da adoção dessa técnica de decidir, aduzindo, no entanto, que a impetração originária fez referência à inexistência de abalo à ordem pública e de risco concreto de fuga, mas o acórdão combatido não analisou tais questões. (HC 276.991/RS, Rel. Ministra LAURITA VAZ, QUINTA TURMA, julgado em 05/08/2014, DJe 21/08/2014)

29 Cf. informativo n. 436, STF.

${ }^{30}$ DIDIER JR., Fredie; BRAGA, Paula Sarno; OLIVEIRA, Rafael Alexandria de. Curso de Direito Processual Civil. $8^{\text {a }}$ ed. Salvador: Jus Podivm, 2013, p. 85.

31 “Apesar de exigir grande cautela por parte dos magistrados, a fundamentação implícita torna-se possível apenas para os casos que a análise de determinada questão torna-se irrelevante pela posição tomada na causa, ou
} 
Não se trata de simplesmente o magistrado adotar as razões expedidas por um dos integrantes do processo. ${ }^{32}$ Implícita é a fundamentação "que existe, embora não representada na sentença por símbolos gráficos, é dedutível por processo mental e lógico". ${ }^{33}$

Assim sendo, não há necessidade de análise de todos os fundamentos suscitados pelas partes pelo juiz da causa. ${ }^{34}$ Se o necessário para uma justificação adequada da decisão for concluída, da qual o juiz registra seus critérios de escolha dentre os argumentos já existentes, argumentos inúteis ou despiciendos, evidentemente, devem ser rechaçados. ${ }^{35}$

\section{Do dever de fundamentação das decisões judiciais no novo Código de Processo Civil}

\section{(Lei n. 13.105/2015)}

O novo diploma processual civil (NCPC) reconhece e confere normatividade a diversos princípios, positivando-os em seu texto. Dentre os quais destaque para o art. 11.

Ao lado do princípio constitucional e legal, a nova lei, ${ }^{36}$ no art. 489 , com o fim de alcançar a adequada fundamentação às decisões judiciais, elenca de modo exemplificativo critérios

seja, quando a negativa de determinada questão secundária está implícita na negativa da principal - se não há principal não há acessório. Por entendermos que o magistrado está obrigado a se pronunciar sobre todos os argumentos e pretensões das partes, se o magistrado nega fundamentadamente algo que seja principal, os seus respectivos acessórios restarão implicitamente improcedentes, ou melhor, restarão por prejudicados, dispensando fundamentação expressa. Ademais, é admissível também em caso de teses contrapostas, em que o acolhimento fundamentado de uma acaba por rejeitar de forma reflexa a outra." MIRANDA, Felipe Arady. A fundamentação das decisões judiciais como pressuposto do Estado Constitucional. Brasília: IDP, 2014. Disponível em http://www.idp.edu.br/publicacoes/portal-de-ebooks230p. Acesso em: 20 de julho de 2015, p. 207.

32 TUCCI, 187, p. 153.

${ }^{33}$ PERO, Maria Thereza Gonçalves. A motivação da sentença civil. São Paulo: Saraiva, 2001, p. 95.

${ }^{34}$ A sentença deveria analisar todas as questões suscitadas, mas o próprio CPC vigente deixa margem para que isso não ocorra no art. $151, \S 1^{\circ}$.

${ }^{35}$ Inexiste violação do art. 535, II, do Código de Processo Civil quando o aresto recorrido adota fundamentação suficiente para dirimir a controvérsia, sendo desnecessária a manifestação expressa sobre todos os argumentos apresentados pelos litigantes. (REsp 1407862/RO, Rel. Ministro MAURO CAMPBELL MARQUES, SEGUNDA TURMA, julgado em 09/12/2014, DJe 19/12/2014)

É entendimento desta Corte de Justiça que não há necessidade de que o julgador refute expressamente todas as teses aventadas pela defesa, desde que pela motivação apresentada seja possível aferir as razões pelas quais acolheu ou rejeitou as pretensões da parte. Precedentes STJ. (HC 217.660/DF, Rel. Ministro JORGE MUSSI, QUINTA TURMA, julgado em 16/05/2013, DJe 29/05/2013)

${ }^{36}$ Repetindo o texto do CPC vigente, temos ainda expresso o princípio do livre convencimento motivado no art. 371 do NCPC: "O juiz apreciará a prova constante dos autos, independentemente do sujeito que a tiver promovido, e indicará na decisão as razões da formação de seu convencimento.” 
objetivos $\left(\S 1^{\circ}\right)$ a serem observados por quaisquer magistrados, desde titulares de varas de juizados especiais até ministros do Supremo Tribunal Federal.

O dispositivo 489 vem sendo apontado pela doutrina com um dos mais importantes do NCPC, mormente o estatuído em seu $\S 1^{\circ}$, e não é para menos. O mencionado parágrafo exige a observância dos mesmos parâmetros para todos os tipos de decisão (sentença, acórdão e interlocutória) e por todos os magistrados, independentemente de sua hierarquia funcional, devendo, pois, a regra ser observada tanto por um juiz titular de juizado especial cível quanto por um ministro do Supremo Tribunal Federal.

Ainda somos uma sociedade com cultura jurídica marcadamente positivista. Critérios mínimos e objetivos para uma adequada fundamentação devem ser vistas com bons olhos sim. $\mathrm{Na}$ ausência de parâmetros práticos, a fundamentação das decisões sempre foi matéria polêmica por ficar a mercê do subjetivismo do julgador, em uma zona cinzenta. Por isso não é raro depararmos com decisões simplórias, fundamentações inócuas e/ou inexistentes.

Como sabido, a partir da vigência do Código Civil de 2002, a CF88 passou a ser incorporada à hermenêutica processual, exsurgindo os ditames de um processo civil constitucional. $\mathrm{O}$ Estado Constitucional é formado pelo Estado de Direito (com enfoque na estabilidade e previsibilidade) e pelo Estado Democrático. Diante deste novo paradigma, a CF88 passou a ser levada às últimas consequências interpretativas e o NCPC positivou esta postura (art. $1^{\circ}$ ).

O Poder Judiciário, como integrante de um Estado Constitucional, também segue as diretrizes administrativas do art. 37 da CF88, dentre os quais o princípio da eficiência, que exige dos gestores da coisa pública esforço no desempenho de seus encargos de modo a otimizar o emprego dos recursos que a sociedade destina para a satisfação das suas múltiplas necessidades. ${ }^{37}$

\footnotetext{
${ }^{37}$ MENDES, Gilmar Ferreira; COELHO, Inocêncio Mártires; BRANCO, Paulo Gustavo Gonet. Curso de direito constitucional. $2^{\mathrm{a}}$ Ed. São Paulo: Saraiva, 2008, p. 834.
} 
$\mathrm{O}$ art. 489 traz exigências básicas para uma fundamentação adequada, contentando-se com o básico no modo de atuação do agente público, esperando o melhor desempenho em suas atribuições, visando lograr os melhores resultados. ${ }^{38}$

Eficiência é fazer o básico bem feito. Exige-se dos magistrados o mais basilar dever funcional: decidir e explicar sua decisão, de modo que ele mesmo se convencer de seu julgado. ${ }^{39}$

Especulações negativas sobre o novo dispositivo não devem ser difundidas. Não se pode admitir a cultura da preguiça e da má-vontade intelectual que insiste em se materializar em decisões judiciais simplórias, superficiais e mecanizadas, trazendo inúmeras consequências técnicas trágicas para o ordenamento, como a interposição de incontáveis recursos vazios e procrastinatórios, além de formação de jurisprudência instável.

Importante notar que textos vagos com conteúdos indeterminados, cláusulas gerais e abertas também são modelos de norma. Conforme o disposto no inciso II do dispositivo analisado, conceitos jurídicos abertos robustecem a importância do dever de motivação pelo juiz.

O inciso IV do $\S 1^{\circ}$ do art. 489 , ao prescrever que o juiz deve enfrentar todos os argumentos deduzidos no processo capazes de enfraquecer a sua conclusão, refere-se aos pontos controvertidos, isto é, aos pontos alegados e discutidos pelas partes durante o processo, interpretação esta que ratifica o contraditório substancial.

Ainda, os incisos V e VI do $\S 1^{\circ}$ do art. 489 fortalecem a jurisprudência, dando autoridade inédita aos precedentes, obrigando o julgador a, sempre que invocar ou afastar algum precedente ou enunciado de súmula, procurar e extrair a ratio decidendi dos mesmos (incorporando à práxis processual o distinguishing e o overruling). Fortalecer a jurisprudência significa maior previsibilidade, estabilidade/ segurança jurídica, isonomia, celeridade

\footnotetext{
${ }^{38}$ DI PIETRO, Maria Sylvia Zanella. Direito administrativo. $22^{\mathrm{a}}$ Ed. São Paulo: Atlas, 2009, p. 82-83.

${ }^{39}$ LIEBMAN, 1983, p. 80.
} 
processual, desestímulo à litigância (demandas novas e recursos) e credibilidade dos jurisdicionados perante o Poder Judiciário.

\section{Das notas interpretativas relevantes sobre o tema}

Nossa sociedade contemporânea vive sob um "interregno" - típico de uma modernidade líquida (nada é feito para durar), segundo ideias do sociólogo polônes Zygmunt Bauman. Somos mais livres do que nunca, mas ao mesmo tempo impotentes; somos um conjunto de indivíduos frustrado pela falta de agentes, de governo, de instituições coletivas capazes de atuar efetivamente, e, por isso, este dito interregno: antigos procedimentos já não funcionam e formas de resolver os problemas de uma nova maneira efetiva ("novos arranjos") ainda não existem ou não as conhecemos. ${ }^{40}$

Modernização significa não aceitar as coisas como elas são, e sim transformá-las em algo que consideramos melhor. Modernizamos obsessivamente as regras, os objetos, os costumes. Não duram muito tempo. Isso é o mundo líquido. Fazendo-se um "link" com nossa temática, em uma sociedade em que ninguém se sente seguro, muita desconfiança e descrédito também permeia a atividade jurisdicional do ponto de vista de doutrinadores, juristas militantes e jurisdicionados (cidadãos).

O NCPC tem sido alvo de elogios, mas também de inúmeras críticas.

$\mathrm{O}$ art. 489 do NCPC (c/c arts. 11 e 371, entre outros), que positivou e elencou "novos" requisitos à fundamentação das decisões judiciais, tem sido apontado como um dos "corações" do NCPC.

Muitos doutrinadores renomados, desacreditados na estrutura administrativa do Poder Judiciário, especulam que o dispositivo tende a não ser respeitado, a cair em desuso, a ser uma

${ }^{40}$ BAUMAN, Zygmunt. Amor líquido - sobre a fragilidade dos laços humanos. Tradutor: Carlos Alberto Medeiros. Jorge Zahar Editor, 2004.

e-ISSN: 2525-9822 | Curitiba | v. 2 | n. 2 | p. 21 - 42 | Jul/Dez. 2016. 
regra estéril. Isto porque creem erroneamente, data vênia, que o novo regramento, além de utópico, quase poético, contraria, na prática, a celeridade processual.

Muitas vezes o juiz, analisando os argumentos trazidos e as provas produzidas no processo, tende a primeiramente escolher a tese do vencedor e somente depois justificar tal opção, o que não se coaduna com o paradigma do NCPC. A fundamentação não deve se ater à justificação da tese vencedora, mas deve precisamente expor por quais razões a tese sucumbente não foi digna de prosperar, por que as alegações e provas trazidas pela parte derrotada não lhe bastaram à formação do convencimento, coadunando-se, pois, com os ditames do contraditório substancial. ${ }^{41}$

No contexto de um Estado Constitucional, os princípios processuais constitucionais devem ser analisados e interpretados em conjunto para garantir a integridade do Direito e sua melhor aplicabilidade para fins de pacificação social.

O processo deve realizar os direitos fundamentais dos cidadãos, portanto.

Sob a batuta do princípio do devido processo legal, nenhuma arbitrariedade é admissível; todo ato injusto e arbitrário poderá ser considerado inconstitucional. ${ }^{42}$ Assim, uma decisão para ser adequada necessita ser racionalmente explicada; a fundamentação coerente das decisões judiciais é tanto m dever do julgador quanto uma garantia ao cidadão de ter seu litígio julgado de acordo com o devido processo legal. ${ }^{43}$

É interessante notar que o NCPC é extremamente exigente para a advocacia e todas as partes do processo. O saneamento o processo, por exemplo, será compartilhado, ou seja, será

\footnotetext{
${ }^{41}$ MIRANDA, 2014, p. 206.

${ }^{42}$ BONAVIDES, Paulo. Curso de direito constitucional. 9. ed., São Paulo: Malheiros, 2000, p. 388.

43 STRECK, Lênio Luiz. Verdade e consenso: constituição, hermenêutica e teorias discursivas. 5. Ed. São Paulo: Saraiva. 2014, p. 96.
} 
realizado com base nas discussões efetuadas segundo previsão expressa no art. 357 do NCPC, mais precisamente parágrafos $1^{\circ}$ e $3^{\circ} .^{44}$

As normas fundamentais do processo civil (arts. $1^{\circ}$ a 12 do NCPC) possuem elevadíssima carga normativa, tendo em vista o paradigma democrático do Estado. O processo é democrático.

Desse modo, em conjunto com as demais normas principiológicas e da garantia fundamental da motivação das decisões judiciais, o princípio do contraditório é o "reflexo do princípio democrático na estruturação do processo. Democracia é participação, e a participação no processo opera-se pela efetivação da garantia do contraditório."45

O contraditório participativo precisa ser encarado em sua dimensão substancial, tríade ou tridimensional. Isso significa que para as partes do processo deve ser dada oportunidade de influir na formação da decisão final, de participação ativa. Quaisquer manifestações e provas produzidas por qualquer uma das partes, em igualdade de condições, devem ser analisadas e valoradas pelo juiz (as razões das partes agora devem integrar a decisão final). O contraditório é mais que o direito tradicional de ter informação e de participar, é direito de influência (esta seria a terceira dimensão do princípio). ${ }^{46}$

Manifestando-se sobre o controle racional das decisões judiciais, Teresa Arruda Alvim Wambier assevera que a técnica de pensar e resolver os problemas se desenvolve no seio da retórica dialética, ou seja, da arte de persuasão conjunta, superando-se o rigor lógico formalista/ legalista das tomadas de decisões:

\footnotetext{
${ }^{44}$ Art. 357. Não ocorrendo nenhuma das hipóteses deste Capítulo, deverá o juiz, em decisão de saneamento e de organização do processo: (...) $\S 1^{\circ}$ Realizado o saneamento, as partes têm o direito de pedir esclarecimentos ou solicitar ajustes, no prazo comum de 05 (cinco) dias, findo o qual a decisão se torna estável. (...) $\S 3^{\circ} \mathrm{Se}$ a causa apresentar complexidade em matéria de fato ou de direito, deverá o juiz designar audiência para que o saneamento seja feito em cooperação com as partes, oportunidade em que o juiz, se for o caso, convidará as partes a integrar ou esclarecer suas alegações.

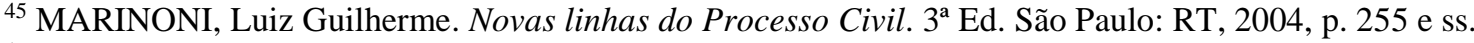

46 MIRANDA, Felipe Arady. A fundamentação das decisões judiciais como pressuposto do Estado Constitucional. Brasília : IDP, 2014. Disponível no http://www.idp.edu.br/publicacoes/portal-de-ebooks 30p. Acesso em: 20 de julho de 2015, p. 72.
} 


\begin{abstract}
O método sistemático toma como ponto de partida uma verdade primeira, um axioma, e procede por meio de uma série de rigorosas deduções semelhantes às da matemática. Ao contrário, a retórica dialética toma como ponto de partida o sentido comum, tateando o caminho no campo da verossimilhança guiando-se pela prudência humana. Para isso, as circunstâncias são consideradas sob seus mais diversos aspectos, e é ponderada a força de convicção de cada um dos pontos de vista. Procura-se qual das opiniões tem maior força persuasiva e conduz a um resultado mais plausível. ${ }^{47}$
\end{abstract}

Neste ínterim, as partes, tendo o poder e a garantia de interferir no desfecho final do processo, devem se sentir seguras durante todo o procedimento, afinal o processo se trata (ou deveria se tratar) de um diálogo cooperativo e democrático.

Portanto, o $§ 1^{\circ}$ do art. 489 do NCPC, alvo de contundentes críticas doutrinárias, apesar de ser direcionado aos magistrados, ao estabelecer requisitos objetivos orientadores de uma fundamentação adequada, não pode ser interpretado de maneira isolada.

Como vimos, o desfecho final do processo é construído pelas partes, iniciando-se pela petição inicial bem fundamentada, passando pela instrução substancialmente participativa e pelo saneamento compartilhado. A sentença representa tudo o que ocorreu no processo; é, logo, produto do esforço conjunto.

Por isso mesmo que ao juiz é imposto um limite, qual seja, decidir somente acerca das questões de fato e de direito das quais foram objeto de discussão (trata-se da garantia de não surpresa decorrente do princípio do contraditório). ${ }^{48}$

Isto posto, a exegese do dever e da garantia de fundamentação das decisões judiciais como indicado no NCPC merece consideração sistemática, mormente a partir de uma construção participativa obrigatória das partes do processo. Somente assim podemos traçar as considerações necessárias e extremamente positivas às inovações inseridas no NCPC.

\footnotetext{
${ }^{47}$ WAMBIER, 2007, p. 318-320.

${ }^{48}$ MIRANDA, 2014, 74-75.
} 


\section{Das considerações finais}

O atual paradigma do Estado Constitucional requer participação democrática das partes na construção do provimento jurisdicional. O processo serve, pois, para realizar os direitos fundamentais.

Diante deste paradigma, a construção participativa é exigência para fins de fundamentação das decisões judiciais, momento em que o juiz além de considerar os argumentos aduzidos pelas partes não poderá ultrapassar a matéria discutida nos autos, em respeito ao contraditório substancial.

Um novo código revela que a sociedade mudou, não o processo ou o Poder Judiciário. A sociedade exige mudanças, exige concretização dos direitos fundamentais no processo.

Um novo código de processo representa mudança de paradigma, ou seja, um "pensar novo"; não significa reforma processual, mas sim uma ruptura sistemática.

Assim, sem uma mudança paradigmática, pra quê um novo código?

Em relação à fundamentação das decisões, é imprescindível também um novo olhar. Sua interpretação deve ser conjunta com os demais princípios processuais fundamentais e sistemática com os novos paradigmas do processo.

Como já tivemos oportunidade de expor, destaque para a decisão saneadora que se tornará um dos momentos mais importantes do processo: indicação do ônus da prova, delimitação do que é juridicamente relevante e a delimitação dos debates entre as partes; eis o escopo desta fase.

$\mathrm{O} \S 1^{\circ}$ do art. 489 do NCPC, apesar de ser direcionado aos magistrados, não pode ser interpretado de maneira isolada uma vez que o desfecho final do processo é construído pelas partes. A sentença representa tudo o que ocorreu no processo; é, logo, produto do esforço conjunto. 
Comungamos da opinião de Daniel Carneiro Machado em que o dever de considerar os argumentos das partes na decisão não pode ser visto de forma absoluta. Interpretação contrária poderia acarretar abusos e engessar a atividade jurisdicional na medida em que o juiz seria obrigado, em qualquer caso, a responder questionários e analisar todas as questões levantadas no processo, mesmo as incapazes de infirmar o julgamento. Assim, a melhor interpretação é que o julgador deverá analisar detidamente apenas os argumentos considerados relevantes e previamente delimitados na fase do saneamento. ${ }^{49}$

É claro que os requisitos objetivos de uma decisão adequadamente fundamentada elencados no $\S 1^{\circ}$ do art. 489 não garante isoladamente a melhora da qualidade do trabalho do magistrado, mas evidencia os anseios da sociedade quanto a efetividade da prestação jurisdicional, além de criar critérios para a uniformização da jurisprudência.

Como vimos, o dever e a garantia de fundamentação é direito fundamental e serve de controle da participação efetiva das partes no processo, corolário do princípio do contraditório enquanto direito de influência e garantia da não-surpresa. Por isso o art. 489 positiva o princípio da cooperação e do contraditório como norteadores da condução do processo.

Decisão adequadamente fundamentada é decisão democrática; não podendo ser apenas taxada de dever excessivamente trabalhoso e complexo. Afinal, não se transige com direitos fundamentais; a balança não pende igual e constitucionalmente na troca de menos fundamentação das decisões por mais julgamentos.

\section{REFERÊNCIAS BIBLIOGRÁFICAS}

AINIS, MICHELE. La motivazione in fatto della sentenza costituzionale. Rivista Trimestrale di Diritto e Procedura Civile. Milano: Anno 48, n. 1, mar. 1994.

${ }^{49}$ MIRANDA, 2014, p. 79. 
BAUMAN, Zygmunt. Amor líquido - sobre a fragilidade dos laços humanos. Tradutor: Carlos Alberto Medeiros. Jorge Zahar Editor, 2004.

BONAVIDES, Paulo. Curso de direito constitucional. 9. ed., São Paulo: Malheiros, 2000.

CARNEIRO, Athos Gusmão. Sentença mal fundamentada e sentença não fundamentada. In: RePro, n. 81, São Paulo: RT, 1996.

CARNELUTTI, Francesco. Diritto e Processo. Giuffré Editora: Nápoles, 1958.

CARRILlo, MARC. Poder Judicial y Estado Democrático. In: POLETTI, RONALDO REBELLO DE BRITO (org.). Notícia do Direito brasileiro. Brasília: Nova Série, n. 9, 2002.

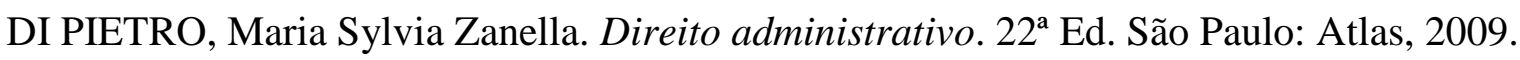

LIEBMAN, Enrico Tulio. Do arbítrio à razão. Reflexão sobre a motivação da sentença. In: RePro, n. 29. São Paulo: RT, 1983.

DIDIER JUNIOR, Fredie; BRAGA, Paula Sarno; OLIVEIRA, Rafael Alexandria de. Curso de Direito Processual Civil. $8^{a}$ ed. Savador: Jus Podivm, 2013.

FREITAS, Franchesco Maraschin. O estado democrático de direito: a fundamentação das decisões judiciais como concretização da contemporaneidade jurídica. Revista da faculdade de direito da UERJ- RFD, n. 27, 2015, p. 18-42.

LAZZARI, João Batista. A argumentação jurídica e a fundamentação das decisões proferidas no âmbito dos juizados especiais. Revista Jurídica, v. 18, n. 35, p. 215-229, jan./abr. 2014.

MACHADO, Daniel Carneiro. A visão tridimensional do contraditório e sua repercussão no dever de fundamentação das decisões judiciais no processo democrático. In: Rev. SJRJ. Rio de Janeiro, v. 21, n. 41, Dez. 2014, p. 69-85. 
MARINONI, Luiz Guilherme. MITIDIERO, Daniel. O Projeto do CPC. Crítica e propostas. Editora RT. 2010.

; ARENHART, Sérgio Cruz. Manual do processo de conhecimento. $4^{\mathrm{a}}$ Ed. São Paulo: RT, 2005.

Novas linhas do Processo Civil. $3^{\mathrm{a}}$ Ed. São Paulo: RT, 2004.

MENDES, Gilmar Ferreira; COELHO, Inocêncio Mártires; BRANCO, Paulo Gustavo Gonet. Curso de direito constitucional. $2^{\text {a }}$ Ed. São Paulo: Saraiva, 2008.

MOREIRA, José Carlos Barbosa. A motivação das decisões judiciais como garantia inerente ao Estado de Direito. In: Temas de direito processual. 2a série. São Paulo: Saraiva, 1998.

MIRANDA, Felipe Arady. A fundamentação das decisões judiciais como pressuposto do Estado Constitucional. Brasília : IDP, 2014. Disponível no http://www.idp.edu.br/publicacoes/portal-de-ebooks30p. Acesso em: 20 de julho de 2015.

NAVARRETE, ANTONIO MARIA LORCA. La necesaria motivación de las resoluciones judiciales. Revista de Informação Legislativa. Brasília: ano 25, n. 100, out./dez. 1988.

ORDÓÑEZ, David Solis. Jueces, derecho y política: Los poderes deljuez em uma sociedad democrática: Aranzadi, 2004

PERO, Maria Thereza Gonçalves. A motivação da sentença civil. São Paulo: Saraiva, 2001.

ROMÃO, Pablo Freire. Contraditório, cooperação e precedente: a ampliação do diálogo processual sob a ótica do novo código de processo. Revista Eletrônica de Direito Processual - REDP. Volume 15. Janeiro a Junho de 2015, p. 377-416. 
STRECK, Lênio Luiz. Verdade e consenso: constituição, hermenêutica e teorias discursivas. 5. ed. São Paulo: Saraiva. 2014.

TARUFFO, Michele. Il significato constituzionale dell'obbligo di motivazione. In: Participação e Processo (Coord.: Dinamarco, Grinover e Watanabe). São Paulo: RT, 1988.

TUCCI, José Rogério Cruz e. A motivação da sentença no processo civil. São Paulo: Saraiva, 1987.

VIANA, Juvêncio Vasconcelos; MAIA, Gretha Leite; AGUIAR, Ana Cecília Bezerra de (ORG). O Projeto do Futuro CPC: tendências e desafios de efetivação. Fortaleza: CRV, 2013.

WAMBIER, Teresa Arruda Alvim. Nulidades do processo e da sentença. $6^{\mathrm{a}}$ ed. São Paulo: RT, 2007. 